\title{
PROCESSO DE FORMAÇÃO ESPORTIVA: PONTOS DE VISTA DE UMA CAMPEÃ A PARTIR DE SUA EXPERIÊNCIA PESSOAL - ENTREVISTA COM MAGIC PAULA *
}

Hermes Ferreira Balbino

\section{Resumo}

O Esporte tem sido reconhecido como um fenômeno social de significativa importância na vida das pessoas. Esta entrevista, que tem como cenário os jogos esportivos coletivos, mais especificamente a modalidade basquetebol, tem como objetivo colher registros da opinião de uma relevante integrante da história do Esporte do Brasil. Os temas tratados dialogam na esfera de elementos relacionais que envolvem desde o processo de iniciação esportiva ate o esporte profissional, tendo como referencia a experiência pessoal de sucesso da ex-atleta Maria Paula Gonçalves da Silva, nomeada pela Mídia como Magic Paula.

\section{Palavras-Chave:}

Jogos esportivos coletivos; Basquetebol; Magic Paula.

\section{SPORTIVE FORMATION PROCESS: POINTS OF VIEW OF A CHAMPION FROM HER PERSONAL EXPERIENCE - AN INTERVIEW WITH MAGIC PAULA}

Hermes Ferreira Balbino

\begin{abstract}
The Sport has been recognized as a social phenomenon of significant importance in people's life. This interview, which has the collective sportive games as scenery, more specifically the basketball modality, aims to collect opinions from an important integrant of the Brazilian sport history. The considered issues concern subjects varying from sportive initiation process to professional sport, having as reference the personal experience of success of the former-athlete Maria Paula Gonçalves da Silva, named by the Media as Magic Paula.
\end{abstract}

Key-Words:

Collective sport games; Basketball; Magic Paula.

* Entrevista realizada em setembro de 2005 pelo Prof. Dr. Hermes Ferreira Balbino e transcrita por Carmen Rosely Silva Concon, Faculdade de Educação Física/UNICAMP 


\section{Introdução}

Maria Paula Gonçalves da Silva nasceu em Oswaldo Cruz, interior do estado de São Paulo em 11 de marco de 1962. Passou por um processo de iniciação esportiva diversificado, orientado pela sua curiosidade e disposição em aprender novas modalidades. Incentivada pelos pais, já aos 10 anos participava de treinamentos e jogos em uma equipe de basquetebol na cidade de Assis.

Sua carreira no basquetebol profissional, com o apoio da família, se desenha a partir dos 14 anos, quando recebe um convite para jogar na equipe de Jundiaí, do Colégio Divino Salvador. Em seguida é convocada pela primeira vez para defender a Seleção Brasileira, sendo a mais jovem integrante do grupo, onde viria a ser titular no ano seguinte, com 15 anos de idade. Em intensa passagem pela iniciação e especialização esportiva, segue definitivamente para esporte profissional e aos 18 anos vai para a equipe da Universidade Metodista de Piracicaba, em que atuou até 1988. Neste ano joga uma temporada pela equipe de Jundiaí, indo para o Tintoretto da Espanha em 1989. Sofre uma grave lesão de joelho, e passa por uma cirurgia de reconstrução de ligamento. Em 1990 volta para o Brasil, atuando pelo BCN na cidade de Piracicaba, e vai para Ponte Preta de Campinas em 1992, atuando pela primeira vez com a companheira de Seleção Nacional, Hortência Marcari, agora juntas em um clube.

Em 1994 volta para Piracicaba, para a equipe do Unimep novamente, indo em 1996 para Campinas, agora pela Microcamp. Em 1999 e 2000 atua pelo BCN, na cidade de Osasco, onde encerra a carreira. As atuações pelos clubes alavancaram sua presença na Seleção Brasileira, tendo participação efetiva na construção do significativo cenário da modalidade no Brasil, confirmado pelos investimentos de diversos patrocinadores, pelo incremento na pratica, profissionalização do contexto de treinamento e pela conquistas internacionais de clubes e da Seleção do Brasil. De maneira significativa, Magic Paula participou da conquista da medalha de ouro em 1991 nos Jogos Pan-americanos de Havana - Cuba, do primeiro lugar no Campeonato Mundial da Austrália, em 1994, sendo considerada uma das melhores jogadoras da competição. Nos Jogos Olímpicos de Atlanta, em 1996, conquistou com a equipe nacional a medalha de prata, oportunidade em que pela primeira vez na historia dos Jogos Olímpicos uma modalidade coletiva fez o encerramento da competição. Participou ainda da conquista da Copa América em São Paulo, trazendo vitória inédita para o Brasil e encerrou sua participação na Seleção Nacional em 1998, com o quarto lugar no Mundial da Alemanha. 
A atuação de Magic Paula no basquetebol mundial é coroada em abril de 2006, com sua indicação para o "Hall da Fama" do Basquetebol, homenagem que se presta aos atletas e técnicos que contribuíram para a divulgação e crescimento da modalidade em todo o mundo.

Tendo seu histórico de vida marcado pela destacada trajetória de desafios que compuseram sua intensa carreira, Magic Paula ocupa hoje, na data da realização desta entrevista, posição na Política Pública Esportiva.

\section{Iniciação Esportiva}

Hermes Ferreira Balbino (HFB) - Como se deu seu processo de formação esportiva?

Maria Paula Gonçalves da Silva (MP) - Começou na escola. Neste espaço comecei a me interessar pelo esporte, tendo como facilitador o fato de ser sócia de um clube da cidade de Oswaldo Cruz, onde nasci no interior de São Paulo. A minha iniciação esportiva se deu através das competições que participava dentro do clube.

HFB - Com que idade começou a praticar as modalidades e quais foram elas?

MP - Entre 08 e 10 anos eu já praticava algumas modalidades. Lembro-me que na escola participei de algumas competições de atletismo, e no clube de competições de natação. Participei de alguns treinamentos: natação, tênis de mesa, xadrez, esses foram os primeiros esportes que eu acabei praticando. Com mais ou menos 10 anos conheci o basquete e comecei a praticá-lo.

HFB - Em quais modalidades você sentia mais prazer em jogar?

MP - Acho que todas; porque comecei jogando como se fosse uma brincadeira de rua. Há 30 anos atrás a gente não pensava no esporte com a dimensão que ele tem hoje. Na minha cabeça o esporte era como se eu estivesse brincando na rua em frente a minha casa. Eu tinha prazer em participar de todos; na verdade o meu grande prazer era competir, disputar medalhas. Tem até uma história interessante: cheguei um dia no clube e vi que tinha uma competição de xadrez - eu sabia movimentar as peças - mas nunca tinha jogado, não tinha técnica, mas, quando vi que só tinha uma menina inscrita falei: "o mínimo que poderia acontecer seria ir embora para casa com uma medalhinha de prata', que foi o que aconteceu. Eu tinha prazer pela competição, pela disputa". 
HFB - Você foi incentivada pelos seus pais, para a prática esportiva?

MP - Eu digo que eles foram meus maiores incentivadores, tanto foram, que numa atitude, louca perante muitos, me mandaram jogar basquete aos 12 anos de idade em uma cidade próxima a Oswaldo Cruz, por acharem que lá eu seria um talento desperdiçado. Para eles eu não estaria na vitrine, não iria estar competindo em campeonatos oficiais, campeonatos de federações; então o incentivo por parte deles foi desde o início, desde pequena.

HFB - E seus Pais acompanhavam você durante os jogos?

MP - Eles me acompanharam em muitos momentos, além do necessário. Hoje eu vejo que não precisava ter sido tanto assim - chegou a ponto de minha mãe se aposentar e começar acompanhar a minha peregrinação pelas cidades em que eu ia jogar. Eles achavam que era importante estar junto de mim, na infância, na passagem da infância para adolescência. Acho que tinha momentos que eu sentia que eles extrapolavam e assim deixavam de ser só pai e mãe para ser tiéte.

HFB - E como é que você se sentia com a presença deles?

MP - No começo foi importante. Depois de um determinado momento começaram a surgir às cobranças. Essas cobranças eram complicadas, porque os pais acham que cobrando eles vão estar ajudando e na verdade isso pode ter um retorno não benéfico para a performance da criança. Eu me considerava uma criança ainda e já tinha que corresponder aquilo que eles exigiam, eu acho que em determinados momentos isso foi bastante prejudicial.

HFB - Oh, eu vou fazer uma pergunta... acho que você já respondeu uma parte, mas se você quiser falar mais eu acho que é interessante. Como se dava a relação estabelecida entre você seus pais e o esporte nesses momentos da de iniciação e como ela se deu depois ao longo de sua vida? Como você vê esse trinômio Paula, os pais e o esporte?

MP - Eu acho que no início a sustentação que eles deram foi importante; depois com a questão da competição acabou sendo mais complicado porque aí começou a se tornar profissional e eles me cobravam demais em determinados momentos - coisas que eu não poderia oferecer - eu estava fazendo meu máximo e às vezes o meu máximo não era o máximo deles. 
HFB - Você esteve presente na seleção desde muito cedo não é? Com quantos anos você recebeu sua primeira convocação?

MP - Ah! Para a seleção adulta fui com quatorze anos.

HFB - Como é que era sua relação com o técnico nesse tempo?

MP - No início foi muito difícil porque eu era a jogadora mais jovem da seleção - muitas vezes era tratada como as demais; a maioria tinha - três, quatro, cinco, seis anos, acima da minha idade - eu era cobrada para ter comportamento igual ao das meninas que conviviam comigo. Outra dificuldade - o técnico levou a grande maioria das jogadoras de seu time e as oportunidades a gente sentia que eram dadas para elas e não para as demais.

HFB - E como era a sua relação com as jogadoras da seleção nesse momento?

MP - Difícil, porque, era uma experiência nova e eu não tinha noção do que aquilo representava na minha vida; o que era estar numa Seleção Brasileira com 14 anos - o que era naquele momento estar concentrada, estar convivendo com 0jogadoras com idade superior a minha.

HFB - Você ocupava desde cedo uma posição de liderança na equipe, jogando como armadora não é? Como é que se deu o seu desenvolvimento nesta posição dentro da quadra?

MP - No início foi aos poucos porque até os quinze anos eu não jogava como titular - tive a primeira oportunidade no Sul-Americano que foi disputado no Perú. Eu era lateral e acabei fazendo a função de armadora. A questão da liderança surgiu aos poucos, no início nem tanto; porque a maioria das jogadoras titulares eram bem mais velhas de time do que eu.

HFB - E como era liderar as pessoas com mais idade que você?

MP - Difícil - toda mudança gera perturbação. O grupo estava passando por uma renovação - algumas jogadoras da geração anterior ainda permaneceram na Seleção - e essa relação foi complicada em relação à conquista da liderança. A conquista da liderança vai acontecendo aos poucos através de sua maneira, de seu jeito de ser. Acho que a liderança imposta não dura por muito tempo.

HFB - A respeito de escola de esporte. Você considera que as escolas de esporte efetivamente podem formar atleta de competição? 
MP - Do jeito que as coisas caminham hoje acho que não. A grande maioria não formará, porque cobra, exige-se da criança e do adolescente comportamento de uma pessoa adulta. Isso na maioria das vezes o acaba prejudicando. Não existe por parte dos adultos - consciência que o indivíduo tem de se formar no contexto global como pessoa e não só a formação de qualidades físicas básicas - já querem estar introduzindo treinamento para essas crianças como se fossem profissionais - na maioria das vezes isso vem a ser ruim para formação do jovem dentro do esporte.

HFB - Como é que você vê o fato de que um dos atrativos para a prática esportiva, nesse tipo do ambiente de formação esteja focado em projetar situações de futuro (como por exemplo, igualar-se às posições dessas crianças num futuro outro a ganhos financeiros que os atletas de destaques ocupam, bem como posições sociais de destaque), para as crianças, isso talvez não ocorra, como é que você enxerga isso aí?

MP - Acho que é mais uma questão de imposição dos pais, que hoje vislumbram o futuro do filho sendo um grande atleta, ganhando muito dinheiro com o esporte - e a gente sabe que para a grande maioria não é assim, são poucos os que terão a oportunidade de sobreviver do esporte. Essa introdução cada vez mais cedo tem sido um grande problema - o atleta tem que ser vencedor; tem que pensar que o seu futuro; tem que ganhar dinheiro; tem que ser o melhor; e a gente sabe que muitas vezes isso não acontece, a gente sabe que a chance é uma entre mil. Um deles vai ter essa oportunidade e é ai que gera o processo de frustração nessa garotada - futuramente eles vão poder sentir isso se de repente não chegarem no que projetaram para eles, ou não conseguir alcançar aquilo que outras pessoas projetaram pra vida deles.

HFB - Existe uma competição com o outro e união no próprio grupo para conseguir atingir os objetivos e resultados da equipe. Você considera que esta relação se modifica de alguma maneira quando no profissionalismo há competição interna pelos melhores salários ou posições de destaque na equipe?.

MP - Enquanto cada atleta não perceber que o "eu", a "vaidade", o "ego" tem que ficar bem escondidinho e abaixo dos objetivos do grupo, este nunca chegará a lugar nenhum. É difícil você ter um grupo em que cada um pensa em si, é vaidoso e acha que tudo tem que ser da forma ou da maneira dele, este jamais vai conseguir um resultado positivo, vai ficar penando por muito tempo até que se dê chance de reconhecer que este tipo de comportamento não leva a lugar nenhum. Nós somos grandes exemplos disto - enquanto cada um ficou pensando em si, o basquete feminino não conseguiu chegar a lugar nenhum, a partir do momento que cada um foi vendo que era importante numa determinada função dentro da equipe, a equipe chegou. Isto, demora para as pessoas reconhecerem e entenderem, acho que vem só com a maturidade, 
mas, a gente não pode ficar esperando muito tempo, esperando que a maturidade chegue com o passar dos anos, pode ser realizado um trabalho para demonstrar que todos juntos, cada um desenvolvendo suas funções, vai ser mais interessante e não cada um achando que é mais importante que o grupo.

HFB - Então, na sua percepção, como é ao mesmo tempo jogar junto e entre outros momentos jogar competindo internamente com os colegas?

MP - Eu acho que é um equivoco, enquanto se pensar desta forma não se chegará a lugar algum, penso que o adversário tem que ser o "outro", não pode estar na mesma equipe que você, que está na luta, na batalha - o inimigo é o adversário e não quem participa do seu grupo.

HFB - Hoje, atuando com as políticas públicas, o que você deseja viabilizar às crianças que se iniciam na prática, que você não teve quando começou a praticar modalidades esportivas e considera importante para o processo de formação esportiva do indivíduo?

MP - A minha grande preocupação é de que os educadores não estejam preocupados somente em formar atletas e sim que estejam preocupados com o indivíduo, na concepção geral de formar a pessoa. A gente sabe que muitos desses jovens que iniciam no esporte não serão grandes atletas, não vão se destacar na sua modalidade. Sendo assim, acho que a grande preocupação tem que ser em cima de desenvolver neles - a qualidade de cidadão - se ele vai ser um grande atleta ou não, isso vai ser conseqüência de um trabalho. Hoje a gente sente que a maioria dos treinadores e técnicos estão mais preocupados com a formação técnica dos jovens e crianças e começam a praticar o esporte muito cedo, acho que devia ser diferente, esse é o grande objetivo do Centro Olímpico - tentar formar o cidadão como um todo, não só como um grande atleta, ele tem que estudar tem que ser gente acima de tudo.

HFB - E o que você teve na sua formação no seu desenvolvimento, que você gostaria que tivesse também na formação dessas crianças, ou seja, o que você repetiria do que teve e gostaria que as pessoas tivessem também?

MP - O esporte perdeu muito com a profissionalização. A profissionalização fez com que as pessoas perdessem a noção da importância que cada coisa representa na evolução de sua performance. É necessário dar mais valor aquilo que você tem e a profissionalização está fazendo com que isso vá se acabando - a gente tem que curtir cada momento, cada conquista. As conquistas têm que ser suadas tem que ser como uma escada, para você pouco a pouco ir conquistando seus degraus. Não se deve pular fases, de repente as fases que você teria que passar você pula e já está numa fase acima, eu gostaria de 
voltar naquele tempo em que eu treinava três vezes por semana, depois passei a treinar uma vez por dia, depois duas vezes por dia, quer dizer que esse processo seja um pouco mais lento, que a profissionalização seja mais lenta.

HFB - Em relação às políticas públicas, com o contexto que nos temos hoje no Esporte Nacional, como você vê projetado esse contexto para daqui a dez anos?. Considerando que você é uma pessoa importante na formação desse contexto, e que muitas coisas podem acontecer daqui pra frente?

MP - Não vejo muitas mudanças para daqui a dez anos, porque vivemos em um país que não pensa em formar algo daqui alguns anos, fazer alguma coisa em longo prazo, a gente é muito imediatista, centralizador, não se enxergou o esporte como algo profissional pois deve ser administrado como tal. Ficamos trabalhando como se as coisas fossem acontecer amanhã, então acho que nosso país vai penar por muito tempo ainda em pensar em ser olímpico, enquanto a gente não pensar que o grande responsável por tudo isso é o atleta e pensar que acima de muitas coisas estão os atletas a gente não vai conseguir mudar a cultura do nosso País não. É necessário pensar muito mais do que somos hoje e fazer com que o esporte seja fundamental dentro da escola, na educação. Ele deve ser tratado como qualquer outra disciplina, como a matemática, a ciência, a biologia, a química. Creio que enquanto o esporte não tiver essa função dentro da escola, esse apoio de ser igual ou ser tratado igual às outras disciplinas, não teremos um esporte melhor do que temos hoje.

HFB - Você toca na questão da maturidade do grupo das pessoas para que as conquista viessem. O que você entende como maturidade?

MP - Acho que maturidade a gente vai buscar a vida toda, mas, num determinado momento da nossa vida acabamos encontrando equilíbrio psicológico, físico, técnico. Para mim maturidade representa o equilíbrio entre o físico, psíquico e o espiritual.

HFB - O que você considera Maturidade? Se você quiser pode dar algumas características. MP - Na pergunta anterior disse que maturidade é equilíbrio. Equilíbrio na relação com as pessoas. Equilíbrio para conseguir dosar o que é bom do que é ruim em termos físicos e técnicos para seu rendimento. Através da maturidade conseguimos entender um pouquinho mais quem somos e o que queremos para nossa vida. É tentar fazer com que esta maturidade seja um caminho linear e não tortuoso. Então eu vejo a maturidade como um momento especial na vida de cada um de nós porque esta não é necessária só para você ganhar um título, ela é necessária num relacionamento ela é necessária no seu 
trabalho, no seu dia a dia, ela é necessária na sua família, isso só vem com o tempo, a gente vai amadurecendo conforme se vai errando também, então o amadurecer, pra uns as vezes chega um pouco mais cedo pra outros demoram um pouquinho mais e tem aqueles que vão passar a vida inteira tentando chegar nesse equilíbrio, esse amadurecimento.

HFB - Você encontra essa maturidade em outros espaços, na política ou instituições públicas?

MP - Quando a gente fala de maturidade é claro que você tem que entender cada ser como um ser diferente um do outro, tem muitos que acham que isso não é fundamental, isso não é necessário. Acham que a forma como agem é a forma certa, não estão tentando buscar essa maturidade ao longo dos anos. Então, essa maturidade existe para algumas pessoas e para outras não. Algumas pessoas têm um pouquinho mais de dificuldade de amadurecer. Acredito que o homem amadurece um pouco mais tarde do que a mulher. Então, se a gente está falando de pessoas, quando você fala de maturidade você fala de pessoas, e cada ser é um ser único, cada pessoa tem a sua maneira de encarar as coisas, de vivenciar as coisas e viver à sua maneira. Acreditamos por vezes que fazer esporte é saúde, esporte leva para o bom caminho, ou que é ideal... Nem sempre. Às vezes ele é bom para mim porque eu consegui absorver as coisas interessantes para eu seguir esse caminho. Outras pessoas não entendem dessa forma, ou não entendem por dificuldade ou porque não querem entender ou acham que é uma besteira. Então, maturidade é algo que vamos buscando ao longo da nossa vida, estamos aqui pra crescer amadurecer e para vivenciar todas essas experiências. 
Hermes Ferreira Balbino

Faculdade de Educação Física/UNICAMP 